\title{
Biological performance of a promising Kefiran-biopolymer with potential in regenerative medicine applications: a comparative study with hyaluronic acid
}

\author{
Hajer Radhouani $\mathbb{1}^{1,2,3} \cdot$ Cristiana Gonçalves ${ }^{1,2,3} \cdot$ F. Raquel Maia ${ }^{1,2,3} \cdot$ Joaquim M. Oliveira ${ }^{1,2,3} \cdot$ Rui L. Reis ${ }^{1,2,3}$
}

Received: 20 December 2017 / Accepted: 17 July 2018

(c) Springer Science+Business Media, LLC, part of Springer Nature 2018

\begin{abstract}
Kefiran from kefir grains, an exopolysaccharide (EPS) produced by lactic acid bacteria (LAB), has received an increasing interest because of its safe status. This natural biopolymer is a water-soluble glucogalactan with probed health-promoting properties. However, its biological performance has yet to be completely recognized and properly exploited. This research was carried out to evaluate the in vitro antioxidant and the in vitro anti-inflammatory properties of Kefiran biopolymer. Regarding antioxidant activity, the results demonstrated that the Kefiran extract possessed the strongest reducing power and superoxide radical scavenging, over hyaluronic acid (HA, gold standard viscosupplementation treatment). This exopolysaccharide showed a distinct antioxidant performance in the majority of in vitro working mechanisms of antioxidant activity comparing to HA. Moreover, Kefiran presented an interesting capacity to scavenge nitric oxide radical comparing to the gold standard that did not present any potency. Finally, the cytotoxic effects of Kefiran extracts on hASCs were also performed and demonstrated no cytotoxic response, ability to improve cellular function of hASCs. This study demonstrated that Kefiran represented a great scavenger for reactive oxygen and nitrogen species and showed also that it could be an excellent candidate to promote tissue repair and regeneration.
\end{abstract}

\section{Graphical Abstract}

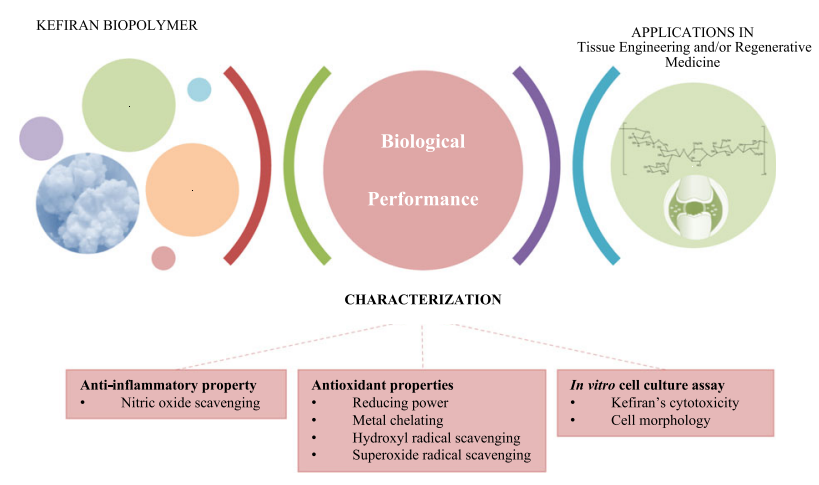

Hajer Radhouani

hajer.radhouani@i3bs.uminho.pt

1 3B's Research Group, I3Bs - Research Institute on Biomaterials, Biodegradables and Biomimetics, Headquarters of the European Institute of Excellence on Tissue Engineering and Regenerative Medicine, AvePark, Parque de Ciência e Tecnologia, Zona Industrial da Gandra, University of Minho, Barco,
Guimarães 4805-017, Portugal

2 ICVS/3B's-PT Government Associate Laboratory, Braga/ Guimarães, Portugal

3 The Discoveries Centre for Regenerative and Precision Medicine, Headquarters at University of Minho, Avepark, Barco, Guimarães 4805-017, Portugal 


\section{Introduction}

Osteoarthritis (OA), a degenerative joint disease, is characterized by cartilage degeneration and osseous overgrowth. This disease is the most common form of arthritis, affecting predominantly the hands, spine, knee and other weight bearing joints, causing a negative impact on the quality of life [1]. Approximately 250 million of people worldwide suffer from OA, causing a substantial socioeconomic burden [2]. Commonly, the clinicians recommend the use of non-steroidal anti-inflammatory drugs (NSAIDs), in order to reduce pain and improve function of the affected joints but it is usually associated with adverse events [1, 3]. Nowadays, the pharmacologic and non-pharmacologic interventions, or the combination of both, are depending on the pain degree and are applied only to manage it, but there are still no effective treatments to reverse the disease [3]. Recently, in the OA context, it has been revealed that the most innovative and promising approach to investigate and treat joint disorders is the use of stem cells or autologous chondrocyte implantation (ACI) [4].

In the last decade, the field of regenerative medicine and tissue engineering has emerged, due to the promising possibility to promote tissue repair and regeneration [5]. Furthermore, regenerative biology has focused on degradable biomaterials, to either release bioactive factors promoting the heal response and/or provide a scaffold seeded by therapeutic cells that can repair and regenerate tissues [6]. Due to the unique structural and compositional similarities of natural extracellular matrix, natural biomaterials have received an increasing interest for engineered tissue scaffolds. Additionally, a key advantage of using these materials is their ability to interact with cells and cellular enzymes, and to be re-modelled and/or degraded when space for growing tissue is needed [7, 8].

Among interesting biomaterials, the most widely used in the biomedical field is hyaluronic acid (HA). It is the main component of the extracellular matrix and its structure, molecular biology and functional properties mediate cellular signaling, wound repair, morphogenesis, and matrix organization [9]. In addition, HA is used in soft tissue augmentation and replacement as well as in surgical diagnostics and procedures [10]. Therefore, HA was considered as gold standard for viscosupplementation, since it is currently used as a commercial injectable biomaterial (e.g. osteoarthritis treatment) [11].

Kefiran is a microbial polysaccharide extracted from the flora of kefir grains; the grains are usually used as a starter of a traditional fermented milk product, originally from Caucasian and Eastern European regions [12]. Furthermore, this exopolysaccharide is a water-soluble branched glucogalactan containing approximately equal amounts of glucose and galactose [13]. This probiotic is produced by lactic acid bacteria, mainly Lactobacillus kefiranofaciens, and also by yeasts. Moreover, Kefiran has been reported to possess several beneficial on human health, which has contributed significantly to the rising interest of this amazing biopolymer in several countries worldwide [14].

In OA disease, human body produces various endogenous systems including reactive oxygen species (ROS) such as nitric oxide (NO) and hydrogen peroxide $\left(\mathrm{H}_{2} \mathrm{O}_{2}\right)$. Thus, damaged tissue remains a challenge to treat due to the limited self-healing capacity of the tissue. This highpoints the need to find new treatment based on biomaterials with unique properties to heal damaged tissue [15].

In the present research, we aim to evaluate by using various in vitro assays the biological properties of Kefiran polysaccharide, particularly its antioxidant property such as reducing power, metal chelating, hydroxyl and superoxide radical scavenging; and its anti-inflammatory property through nitric oxide scavenging in a cell-free system. Moreover, Kefiran's in vitro cytotoxicity and its effect on human adipose-derived stem cells morphology and proliferation were motif of study.

\section{Material and methods}

\subsection{Materials and reagents}

Kefiran polysaccharide was isolated from kefir grains, as previously described in a previous work [16]. For cytotoxicity analysis, the Kefiran samples were filtrated through a $0.22 \mu \mathrm{m}$ filter (Millipore, Billerica, MA).

Hyaluronic acid sodium salt from Streptococcus equi used in this research, is a bacterial hyaluronic acid (HA) which is a natural non-sulphated high molecular weight glycosaminoglycan. HA was provided by Sigma-Aldrich (cat 9067-32-7, 53747).

2-Deoxyribose, ascorbic acid (Vitamin C), ethylene diamine tetra acetate (EDTA), ferric chloride, ferroizine, hydrogen peroxide, iron (II) chloride, iron (II) sulfate heptahydrate, naphthylethylenediamine dichloride, nicotinamide adenine dinucleotide-reduced (NADH), nitroblue tetrazolium (NBT), phenazine methosulfate (PMS), phosphoric acid, potassium ferricyanide, quercetin, sodium hydroxide, sodium nitroprusside (SNP), thiobarbituric acid (TBA), trichloroacetic acid (TCA), sulphanilamide were purchased from Sigma Chemical Co. Milli-Q water was used to prepare reagents for antioxidant and anti-inflammatory assays.

\subsection{Antioxidant activity of Kefiran and hyaluronic acid}

Kefiran and HA samples were prepared in different concentrations $(1$ and $0.5 \%, \mathrm{w} / \mathrm{V})$. The samples were diluted in 
$\mathrm{H}_{2} 0$; and several assays were performed to determine their antioxidant properties: reducing power activity, metal chelating activity, hydroxyl radical scavenging activity and superoxide radical scavenging activity.

\subsubsection{Reducing power activity}

For reducing power assay, the procedure was followed as described by Qi et al. and Singhal et al. [17, 18] with some modifications. Kefiran and HA samples were incubated with potassium ferricyanide $(2 \% \mathrm{w} / \mathrm{V})$ at $50{ }^{\circ} \mathrm{C}$ for $20 \mathrm{~min}$. The reaction was ended by adding trichloroacetic acid $(10 \% \mathrm{w} / \mathrm{V})$ and centrifuge at 4,700 $\mathrm{G}(10 \mathrm{~min})$. The obtained supernatant was mixed with $\mathrm{H}_{2} \mathrm{O}_{2}$ and ferric chloride $(1 \% \mathrm{w} / \mathrm{V})$, and the absorbance was acquired at $700 \mathrm{~nm}$. The assay was carried out in triplicate and ascorbic acid was used as standard.

The reducing power activity of the Kefiran and HA samples was expressed as Ascorbic Acid Equivalent Reducing Capacity (AAEC).

\subsubsection{Metal chelating activity}

Ferrous ion chelating ability of Kefiran and HA samples was determined according to the method of El and Karakaya [19], but modified and adapted to a microplate. Briefly, a reaction mixture, containing $154 \mu \mathrm{L}$ of Kefiran or HA samples $(1 \% \mathrm{w} / \mathrm{V})$, iron (II) chloride $(15 \mu \mathrm{L}, 2 \mathrm{mM})$, was shaken and incubated for $60 \mathrm{~min}$ at room temperature (RT). Ferrozine $(31 \mu \mathrm{L}, 5 \mathrm{mM})$ was added and the absorbance of the mixture was measured at $562 \mathrm{~nm}$ against the blank. The assay was carried out in triplicate and EDTA was used as standard.

The percentage of inhibition of ferrozine- $\mathrm{Fe}^{2+}$ complex formation was given in the following formula:

$$
\begin{aligned}
& \text { Ferrous ions chelating ability }(\%) \\
& \quad=\left[1-\left(\mathrm{ABS}_{\text {sample }} / \mathrm{ABS}_{\text {control }}\right)\right] \times 100
\end{aligned}
$$

$\mathrm{ABS}_{\text {sample }}$ Absorbance in the presence of the sample. $\mathrm{ABS}_{\text {control }}$ Absorbance of the control solution (containing all reagents except Kefiran or HA).

\subsubsection{Hydroxyl radical scavenging activity}

Hydroxyl radical scavenging activity of Kefiran and HA samples was assayed by deoxyribose method [20] with major modifications. Reaction mixture contained $0.45 \mathrm{~mL}$ of sodium phosphate buffer (PBS) $(0.2 \mathrm{M}, \mathrm{pH} 7.0), 0.15 \mathrm{~mL}$ of 2 deoxyribose solution $(10 \mathrm{mM}), 0.15 \mathrm{~mL}$ of $\mathrm{FeSO}_{4}$-EDTA solution (10 mM FeSO, $10 \mathrm{mM}$ EDTA), $0.15 \mathrm{~mL}$ of $\mathrm{H}_{2} \mathrm{O}_{2}$ solution $(10 \mathrm{mM})$ ); and $100 \mu \mathrm{L}$ samples were added to the mixture. Sample solutions were completed to a final volume
(1.5 mL) with $\mathrm{H}_{2} \mathrm{O}$ then incubated at $37^{\circ} \mathrm{C}$ for $4 \mathrm{~h}$. Reaction was stopped by adding $0.75 \mathrm{~mL}$ of TCA solution $(2.8 \% \mathrm{w} / \mathrm{V})$ and $0.75 \mathrm{~mL}$ of TBA solution $(1 \% \mathrm{w} / \mathrm{V}$ in $50 \mathrm{mM} \mathrm{NaOH}$ solution). Solutions were boiled for $10 \mathrm{~min}$ and then cooled. The absorbance was measured at $520 \mathrm{~nm}$ against the blank. The assay was carried out in triplicate and results were expressed in terms of ascorbic acid equivalent antioxidant capacity (AAEC).

Hydroxyl radical scavenging activity (HRSA) of the extract was also reported as \% inhibition of deoxyribose degradation, which is calculated by using the following formula:

$$
\operatorname{HRSA}(\%)=\left[1-\left(\mathrm{ABS}_{\text {sample }} / \mathrm{ABS}_{\text {control }}\right)\right] \times 100
$$

$\mathrm{ABS}_{\text {sample }}$ Absorbance in the presence of the sample, $\mathrm{ABS}_{\text {control }}$ Absorbance of the control solution (containing all reagents except Kefiran or HA).

\subsubsection{Superoxide radical scavenging activity}

Superoxide scavenging of Kefiran and HA samples was determined by the nitroblue tetrazolium (NBT) reduction method with major modifications [21]. Reaction mixture consisted of $500 \mu \mathrm{L}$ of NBT solution $(312 \mu \mathrm{M}$ NBT in $100 \mathrm{mM}$ phosphate buffer), $500 \mu \mathrm{L}$ NADH solution (936 $\mu \mathrm{M}$ NADH in $100 \mathrm{mM}$ phosphate buffer, $\mathrm{pH}$ 7.4) and $250 \mu \mathrm{L}$ of samples was mixed. Reaction was started by adding $250 \mu \mathrm{L}$ of PMS solution to the mixture. After $5 \mathrm{~min}$, absorbance was measured at $560 \mathrm{~nm}$. The assay was carried out in triplicate and results were expressed in terms of ascorbic acid equivalent antioxidant capacity (AAEC).

Superoxide radical scavenging activity (SRSA) of the extract was also reported as \% inhibition of superoxide radical which is calculated by using the following formula:

$$
\operatorname{SRSA}(\%)=\left[1-\left(\mathrm{ABS}_{\text {sample }} / \mathrm{ABS}_{\text {control }}\right)\right] \times 100
$$

$\mathrm{ABS}_{\text {sample }}$ Absorbance in the presence of the sample, $\mathrm{ABS}_{\text {control }}$ Absorbance of the control solution (containing all reagents except Kefiran or HA).

\subsection{Anti-inflammatory activity of Kefiran and hyaluronic acid}

The ability of Kefiran and HA samples to scavenge nitric oxide radical generated in a cell-free system was evaluated according to the method previously described [22] with some modifications. Briefly, $1.5 \mathrm{~mL}$ of sodium nitroprusside $(10 \mathrm{mM})$ and $1.5 \mathrm{~mL}$ of samples were mixed. The samples were incubated at $37{ }^{\circ} \mathrm{C}$ for $150 \mathrm{~min}$. The same volume $(3 \mathrm{~mL})$ of freshly prepared Greiss reagent $(\mathrm{N}-(1-$ Naphthyl)ethylenediamine) was added to the previous mixture. All measurements were taken in triplicate. 
Absorbance of the chromaphore formed during the diazotization of nitrite with sulphanilamide and subsequent coupling with napthylethylenediamme was read at $546 \mathrm{~nm}$ against the blank. The assay was carried out in triplicate and results were expressed in terms of quercetin equivalent antioxidant capacity (QAEC).

The amount of nitric oxide radical inhibition (NORS) was also calculated following using the following formula:

$$
\operatorname{NORS}(\%)=\left[1-\left(\mathrm{ABS}_{\text {sample }} / \mathrm{ABS}_{\text {control }}\right)\right] \times 100
$$

$\mathrm{ABS}_{\text {sample }}$ Absorbance in the presence of the sample. $\mathrm{ABS}_{\text {control }}$ Absorbance of the control solution (containing all reagents except Kefiran or HA).

\subsection{In vitro cell culture studies of Kefiran}

\subsubsection{Human adipose derived stem cells isolation}

Human adipose derived stem cells (hASCs) were obtained from human adipose tissue after liposuction procedure, at Hospital da Prelada (Porto, Portugal), after patient's informed consent and under a collaboration protocol approved by the ethical committees of both institutions. In order to isolate the hASCs, the adipose tissue was submitted to the action of $0.05 \%$ collagenase type II (Sigma), under agitation for $1 \mathrm{~h}$ at $37^{\circ} \mathrm{C}$. Then, it was filter with a strainer and centrifuged at $800 \mathrm{G}$ for $10 \mathrm{~min}$. After discarded the supernatant, pellets were re-suspended in PBS and centrifuged at $350 \mathrm{G}$ for $5 \mathrm{~min}$. Finally, the cell pellet was resuspended in Minimum Essential Media $\alpha$ ( $\alpha$-MEM, Gibco), supplemented with $10 \%$ fetal bovine serum (FBS, Invitrogen), and $1 \%$ antibiotic/antimycotic (Invitrogen). Cultures were maintained at $37^{\circ} \mathrm{C}$ under a humidified atmosphere of $5 \% \mathrm{v} / \mathrm{V} \mathrm{CO}_{2}$ in air. hASCs were selected by plastic adherence and passage at $80 \%$ confluence. hASCs in passage 4 were used for this study.

\subsubsection{Cell culture}

The evaluation of cytotoxicity of Kefiran polysaccharides using hASCs was performed as described for L929 cells line, following ISO 10993-12 (2012) guidelines.

First, hASCs were seeded in each well of a 96-well plate at a density of 3000 cells $/ \mathrm{cm}^{2}$. Then, in accordance with ISO 10993-12, Kefiran sample was prepared (4\% w/V) in $0.9 \%$ w/ $\mathrm{V}$ of $\mathrm{NaCl}$. On the next day, the culture medium was replaced for the previous solution diluted in culture medium at final concentration of $1 \% \mathrm{v} / \mathrm{V}$. Additionally, a negative control (Ctrl-) was prepared composed of culture medium and a positive control $(\mathrm{Ctrl}+)$ composed of Triton X-100 (SigmaAldrich) at a concentration of $1 \% \mathrm{v} / \mathrm{V}$ in culture medium. Cultures were maintained at $37^{\circ} \mathrm{C}$ under a humidified atmosphere of $5 \% \mathrm{v} / \mathrm{V} \mathrm{CO}_{2}$ in air. Finally, at 24,48 and $72 \mathrm{~h}$ of culture, Kefiran's cytotoxicity, cell proliferation and morphology were analyzed as described below.

\subsubsection{Kefiran's cytotoxicity}

Cytotoxicity was assessed using the CellTiter $96^{\circledR}$ AQueous One Solution Cell Proliferation Assay (MTS, Promega). At each time point, 24, 48 and $72 \mathrm{~h}$ cells were incubated with $20 \% \mathrm{v} / \mathrm{V}$ of MTS in culture medium without phenol red (Sigma) for $3 \mathrm{~h}$ at $37^{\circ} \mathrm{C}$. The supernatant was then transferred to a new 96-well plate and absorbance measurements were carried out using a microplate reader (Biotek Synergy HT) at $490 \mathrm{~nm}$.

\subsubsection{Cell morphology}

Cell morphology was studied through F-actin staining. For that, cells were washed with phosphate buffer saline (PBS, Sigma-Aldrich), fixed with 10\% Neutral Buffered Formalin (ThermoFisher Scientific) for $15 \mathrm{~min}$ and permeabilized for 5 min with $0.1 \% \mathrm{v} / \mathrm{V}$ Triton X-100 (Sigma-Aldrich) in PBS. Afterwards, samples were incubated for $30 \mathrm{~min}$ in $1 \% \mathrm{w} / \mathrm{V}$ BSA (Sigma-Aldrich) in PBS to block unspecific binding. Factin filaments were stained with Phalloidin-Tetramethylrhodamine B isothiocyanate (SigmaAldrich, 1:40) and nuclei were counterstained with 1:5000 of the stock of 4,6-Diamidino-2-phenyindole, dilactate solution (DAPI, $1 \mathrm{mg} / \mathrm{mL}$, Biotium). Samples were analyzed by fluorescence inverted microscope (Zeiss Axio observer).

\subsection{Statistical analysis}

All quantitative experiments were run in triplicate and results were expressed as mean values \pm standard deviations. For in vitro cell culture studies, statistical analyses were performed using GraphPad Prism 6.0 software. The non-parametric Mann-Whitney test was used to compare two groups, whereas the comparison between more than two groups was performed using the Kruskal-Wallis test, followed by Dunn's comparison test. The critical level of statistical significance chosen was $p<0.05$.

\section{Results}

\subsection{Antioxidant activity of Kefiran and HA samples}

\subsubsection{Reducing power activity}

In this research, the reducing power assay of Kefiran and HA polysaccharides was performed and the results were shown in Table 1. 
Table 1 Reducing power activity of Kefiran and HA samples

Samples $(\%$ w/V) Ascorbic acid equivalent capacity (AAEC) $(\mu \mathrm{g} /$ $\mathrm{mL}$ of sample solution)

\begin{tabular}{ll}
\hline Kefiran $1 \%$ & $8.47 \pm 0.04$ \\
Kefiran $0.5 \%$ & $4.44 \pm 0.05$ \\
HA $1 \%$ & - \\
HA $0.5 \%$ & - \\
\hline
\end{tabular}

Table 2 Metal chelating activity of Kefiran and HA samples

\begin{tabular}{ll}
\hline Samples $(\%$ w/V) & Iron chelating capacity $(\%)$ \\
\hline Kefiran $1 \%$ & $26.66 \pm 0.05$ \\
Kefiran $0.5 \%$ & $20.19 \pm 0.02$ \\
HA $1 \%$ & $28.5 \pm 0.04$ \\
HA $0.5 \%$ & $24.05 \pm 0.05$ \\
\hline
\end{tabular}

Kefiran showed an interesting reducing power activity, almost $8.5 \mu \mathrm{g}$ AAEC per mL of Kefiran solution $(1 \% \mathrm{wV})$. Contrary to Kefiran polysaccharide, hyaluronic acid did not show any reducing power performance. In fact, Kefiran showed to be a good electron donor that can terminate the radical chain reactions by converting free radicals to more stable products.

\subsubsection{Metal chelating activity}

The metal chelating activity of Kefiran and hyaluronic acid at different concentrations ( 1 and $0.5 \% \mathrm{w} / \mathrm{V})$ were performed in our study. The results of the ferrous ion-chelating effect of Kefiran and HA polysaccharides were shown in Table 2.

Our research demonstrated that the ferrous ion-chelating performance of Kefiran and HA samples were low, compared to EDTA. In fact, these polysaccharides demonstrated almost 27 and $28.5 \%$, respectively, of $\mathrm{Fe}^{2+}$ ion chelating ability at $10 \mathrm{mg} / \mathrm{mL}$ where the standard EDTA showed $91.1 \%$ at a lower concentration $(1.5 \mathrm{mg} / \mathrm{mL})$.

\subsubsection{Hydroxyl radical scavenging activity}

In our research, the scavenging activities on hydroxyl radical of Kefiran and hyaluronic acid were determined and represented in Fig. 1a.

Kefiran and HA samples showed almost the same capacity to scavenge hydroxyl radicals (73.7 and $74.4 \%$, respectively) at $1 \%(\mathrm{w} / \mathrm{V})$. At the two concentrations tested, the scavenging activity of both polysaccharides presented an identical increasing tendency. These results clearly showed that Kefiran and HA polysaccharides have an equally strong scavenging action on $\mathrm{O}_{2}^{-}$. radicals.
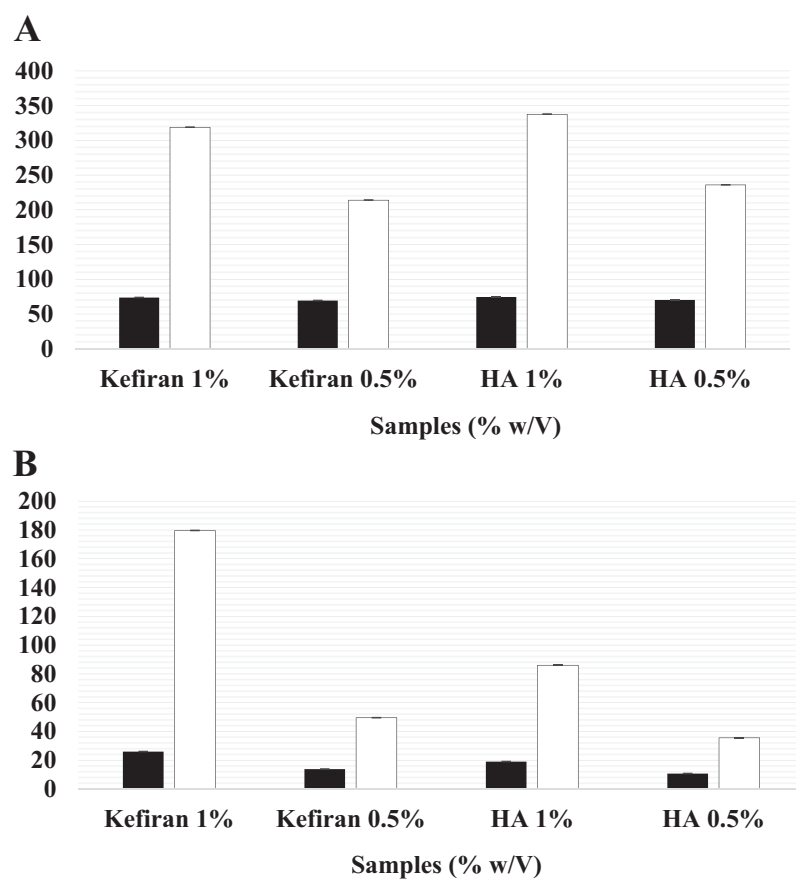

Fig. 1 Hydroxyl $\mathbf{a}$ and superoxide $\mathbf{b}$ radical scavenging activity of Kefiran and HA samples. Inhibition percentage of radical production (black bars) and ascorbic acid equivalent reducing capacity, AAEC (white bars) of Kefiran and HA samples at different concentrations (1 and $0.5 \% \mathrm{w} / \mathrm{V}$ )

\subsubsection{Superoxide radical scavenging activity}

Figure $1 \mathrm{~b}$ presented the superoxide scavenging capacity of Kefiran and HA samples. Kefiran polysaccharide presented a slightly higher capacity to scavenge superoxide radicals than HA (14 and $11 \%$, respectively) at the same concentration $(0.5 \% \mathrm{w} / \mathrm{V})$. In the present study, as shown in Fig. $1 \mathrm{~b}$, the scavenging effects of both polysaccharides were generally enhanced by the increase in concentrations that enriched to $26 \%$ for Kefiran and $19 \%$ for $\mathrm{HA}$ at $1 \% \mathrm{w} / \mathrm{V}$.

\subsection{Anti-inflammatory activity of Kefiran and hyaluronic acid}

Since the presence of an excess of NO radicals in the system is deleterious to human health, it is important to evaluate in vitro the nitric oxide scavenging activity of Kefiran. In this sense, our research aim to evaluate the use of Kefiran polysaccharide as biomaterial for tissue engineering and medicine regenerative applications.

To do so, Kefiran and hyaluronic Acid samples were prepared in different concentrations $(1$ and $0.5 \% \mathrm{w} / \mathrm{V})$ and then diluted in $\mathrm{H}_{2} \mathrm{O}$. The obtained results on nitric oxide scavenging activity were presented in Table 3 .

The results confirmed the interesting capacity of Kefiran to scavenge nitric oxide, especially when compared to HA 
Table 3 Nitric oxide radical scavenging capacity of Kefiran and HA samples

\begin{tabular}{lll}
\hline $\begin{array}{l}\text { Samples }(\% \\
\text { w/V) }\end{array}$ & $\begin{array}{l}\text { Inhibition percentage of nitric } \\
\text { oxide radical production }(\%)\end{array}$ & $\begin{array}{l}\text { QAEC }(\mathrm{mg} / \mathrm{mL} \text { of } \\
\text { sample solution })\end{array}$ \\
\hline Kefiran $1 \%$ & $40.91 \pm 0.04$ & $0.16 \pm 0.02$ \\
Kefiran $0.5 \%$ & $3.92 \pm 0.03$ & - \\
HA $1 \%$ & - & - \\
HA $0.5 \%$ & - & - \\
\hline
\end{tabular}

that did not present any potency in this assay. In fact, the nitric oxide scavenging activity of Kefiran polysaccharide was about $41 \%$ at $10 \mathrm{mg} / \mathrm{mL}$; whereas, as expected, the standard quercetin showed a more pronounced capacity $(78 \%)$ at a lower concentration $(1 \mathrm{mg} / \mathrm{mL})$.

\subsection{Analysis of cytotoxicity of Kefiran using human primary cells}

In this research, the cytotoxicity of Kefiran extract was assessed using primary cells (human Adipose-derived Stem Cells, hASCs) (Fig. 2). The metabolic activity of cells during $72 \mathrm{~h}$ was performed using MTS assay (Fig. 2a) and the cell morphology was also investigated by means of performing the F-actin staining, along $72 \mathrm{~h}$ of culture (Fig. 2b). In basal culture conditions, hASCs presented a significant increase of metabolic activity along the time. These observations were also corroborated by F-actin staining as illustrated in Fig. 1b. It is interesting to observe that Kefiran extract presented higher metabolic activity than Ctrl-.

Indeed, comparing to the negative control, Kefiran polysaccharide demonstrated higher metabolic activity along time (24, 48 and $72 \mathrm{~h}$ ). Moreover, it is important to point out that images of F-actin and DAPI staining showed no deleterious effect on cell's morphology and demonstrated also an increase on cell proliferation along the incubation time.

\section{Discussion}

Free radicals are atoms or groups of atoms which attack important macromolecules leading to cell damage and homeostatic disruption, causing several inflammatory and degenerative processes such as cancer, neurodegenerative disorders and arthritis, among others [23]. Therefore, intervention of antioxidant molecules is necessary in living cells to interact with these free radicals and terminate the chain reaction in order to prevent cell damage [24].

\subsection{Antioxidant activity of Kefiran and hyaluronic acid}

Regarding the reducing power activity assay, it consists of measuring the electron-donating capacity of an antioxidant compound using the potassium ferricyanide reduction approach. Compounds, having reducing potential, convert the $\mathrm{Fe}^{3+} /$ Ferricyanide complex to the ferrous from which acts as an important indicator of its antioxidant performance [25]. In our research, the reducing power of Kefiran polysaccharide, showed a concentration-dependent response. Same statement was also observed in other polysaccharides from bacteria such as Pseudomanas PF-6 [23] and Peanibacillus mucilaginosus TKU032 [26]. In fact, it has been showed that the exopolysaccharides extracted from these bacteria demonstrated a significant reducing power activity that increase with concentration. The antioxidant activity of a polysaccharide depends mainly on its structural characteristics, including molecular weight, chain conformation, monosaccharide content, and configuration of the glycosidic linkage, among others, and is probably not due to one single factor but to the interaction of several factors [26].

Furthermore, one of the mechanisms of antioxidant defence is chelation of transition metals, thus preventing catalysis of Fenton reactions and hydroperoxide decomposition. The principal strategy to avoid reactive oxygen species generation that is related with redox active metal catalysis implicates chelating of the metal ions [25, 27]. It is important to highlight that generally, the structure of polysaccharide compounds containing more than one of the following functional groups as $-\mathrm{C}=\mathrm{O},-\mathrm{COOH},-\mathrm{O}-,-\mathrm{OH}$, $-\mathrm{PO}_{3} \mathrm{H}_{2},-\mathrm{NR}_{2},-\mathrm{S}$ - and $-\mathrm{SH}$ contribute to its metal chelating performance. Concerning the Kefiran polysaccharide extracted from kefir grains, it has been showed that its chemical structure containing only $\mathrm{O}$ - and - $\mathrm{OH}$ functional groups $[13,16]$. Moreover, the absence of uronic acid and sulfate groups in Kefiran and HA polysaccharides could be an explanation to the low chelating ability of these polysaccharides [28].

The hydroxyl radical $(\mathrm{OH})$ is the most reactive of the oxygen species and causes significant damage to adjacent biomolecules [29]. Several polysaccharides can release hydrogen proton to react with hydroxyl radicals, causing decreased of the rate of hydroxyl radical attack on deoxyribose [30]. A research of Guo and co-workers [31] reported that the inhibition percentage of hydroxyl radical production in exopolysaccharide extracted from Edwardsiella tarda was slightly higher $(90 \%$ at $8 \mathrm{mg} / \mathrm{mL})$ than Kefiran exopolysaccharide extracted in our study (74\% at $10 \mathrm{mg} / \mathrm{mL}$ ) and hyaluronic acid $(74.4 \%$ at $10 \mathrm{mg} / \mathrm{mL})$. It is important to highlight that Kefiran and HA polysaccharides showed almost similar hydroxyl radical scavenging and 
Fig. 2 Kefiran cytotoxicity using human primary cells. a Kefiran extract's cytotoxicity on hASCs cultured during $72 \mathrm{~h}$ assessed by MTS assay. (*) denotes statistical significant differences $(p<0.05)$ along the time of culture. b Cell morphology assessed by $\mathrm{F}$-actin staining (cytoskeleton, red) and counterstained with DAPI staining (nuclei, blue), during $72 \mathrm{~h}$ of culture (scale bar: $50 \mu \mathrm{m}$ )

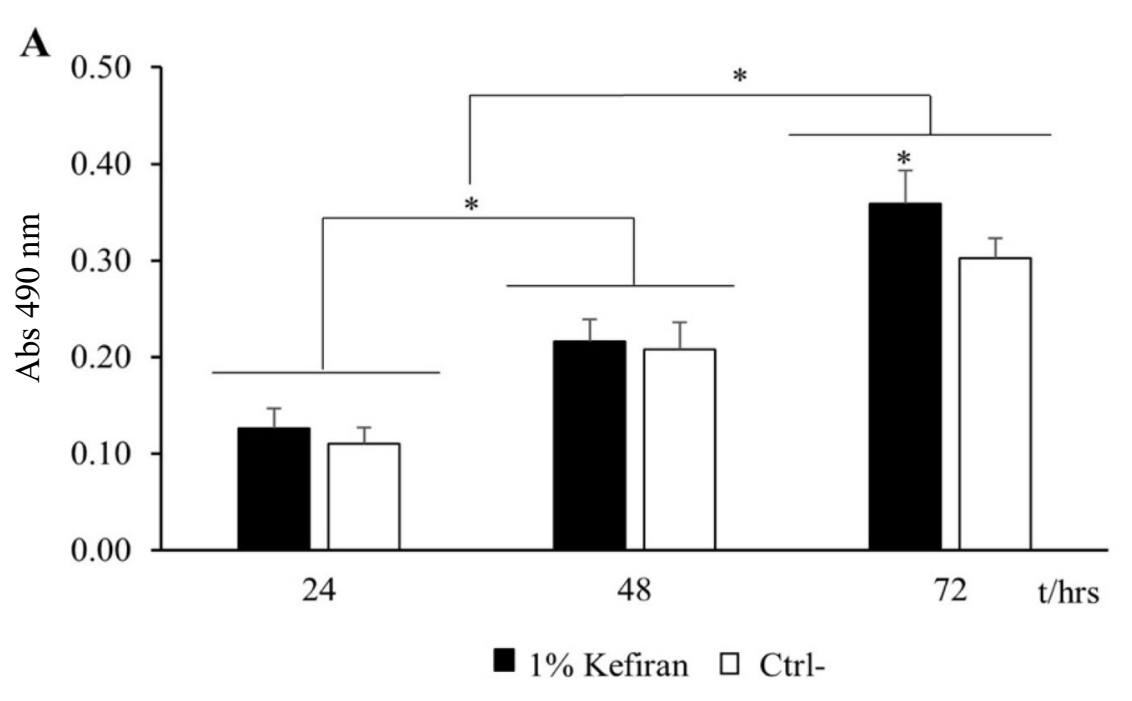

B
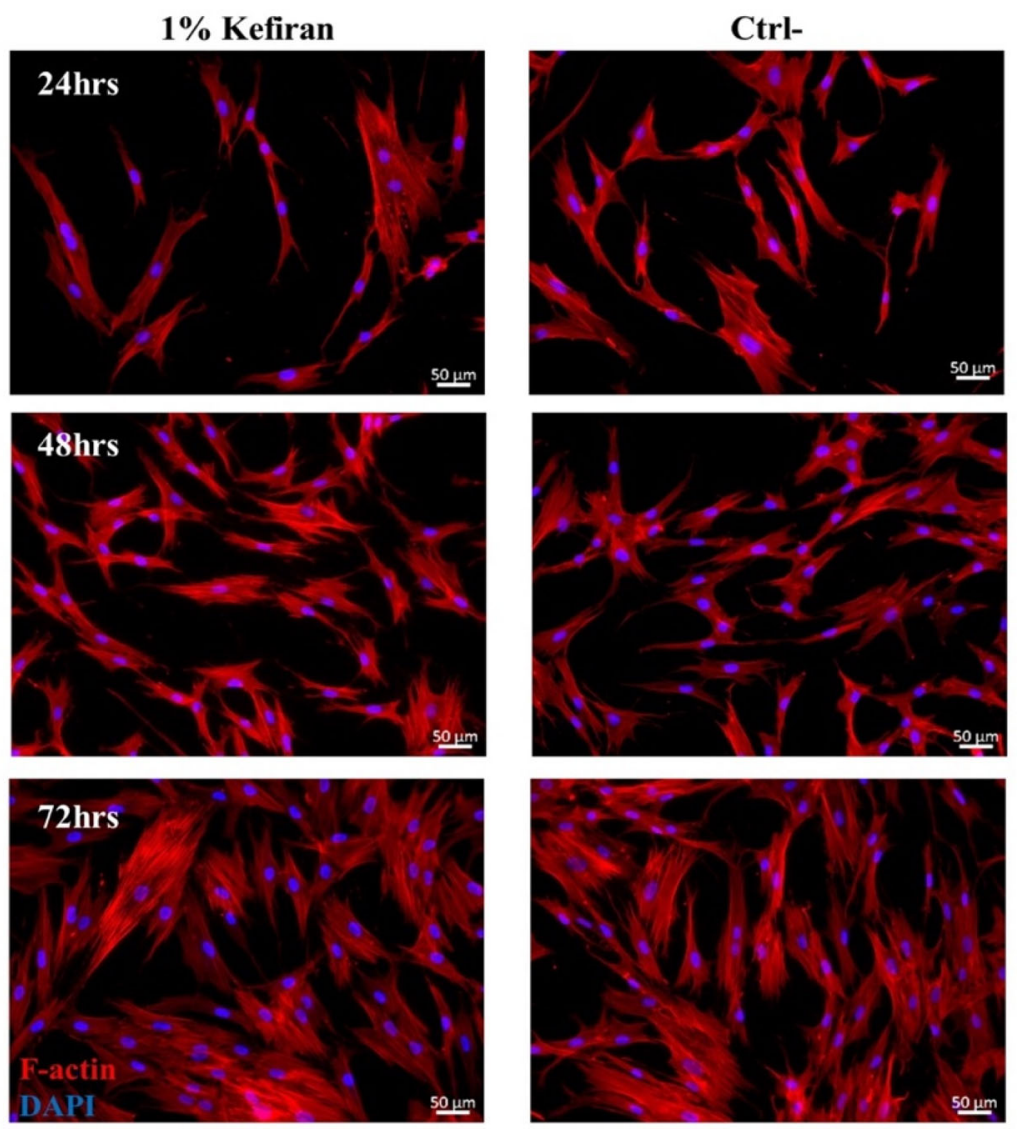

metal chelating activities. This is in agreement with earlier study that reported a similar correlation investigating an extracellular polysaccharide extracted from Nostoc commune [32].

Not to mention that superoxide dismutase (SOD), is one of the most important antioxidative enzymes, catalyzes the dismutation of the superoxide anion $\left(\mathrm{O}_{2}^{-}\right)$into hydrogen peroxide $\left(\mathrm{H}_{2} \mathrm{O}_{2}\right)$ and molecular oxygen. The effect of polysaccharide samples on superoxide generated in a PMS/ $\mathrm{NADH}$ nonenzymic system was measured spectrophotometrically $[33,34]$. In a previous research that studied exopolysaccharide isolated from Pseudomonas PF-6 [23], it has been showed a stronger superoxide radical scavenging activity $(80 \%)$ at a much lower concentration $(0.25 \mathrm{mg} / \mathrm{mL})$ comparing to Kefiran extracted in our research (26\%) at $10 \mathrm{mg} / \mathrm{mL}$. The difference between the 2 
exopolysaccharides could be explained by the fact that the molecular weight of the polysaccharides extracted from these Pseudomonas was higher $\left(8.83 \times 10^{5} \mathrm{Da}\right)$ [23] than Kefiran in this study $\left(1.52 \times 10^{5} \mathrm{Da}\right)$. In fact, polysaccharide molecular weight is one of the most important structural factor in antioxidant performance [31].

Moreover, as mentioned in the literature, the content of protein and pigment in polysaccharide extracts appeared to contribute to a direct scavenging effect on superoxide and hydroxyl radicals which may explain the difference in radical scavenging capacity observed in different polysaccharide extracts $[23,31]$. It is important to highlight that many other factors, such as molecular weight, variation of monosaccharide composition, structure configuration and other chemical components in polysaccharide fractions, were also supposed to play an important role in their antioxidant activities [28].

In this research, it has been showed that Kefiran biopolymer have a high antioxidant potential. In fact, this exopolysaccharide showed a distinct antioxidant activity in the majority of in vitro working mechanisms of antioxidant activity comparing to hyaluronic acid (gold standard in viscosupplementation). There are few references in the literature regarding the antioxidant performance of Kefiran exopolysaccharide isolated from kefir grains, which highlights the importance of the results obtained in our research.

\subsection{Anti-inflammatory activity of Kefiran and hyaluronic acid}

Nitric oxide (NO) is a significant mediator of various physiologic and pathologic processes. NO, a water- and lipid-soluble gas, is perfectly appropriate as a powerful inflammatory mediator due to its strong reactivity with oxygen, superoxide, and iron-containing compounds [23]. The NO does not interact directly with the bioorganic macromolecules, like proteins and DNA. Although, in aerobic conditions, NO is an unstable molecule that interferes with oxygen to produce stable products such as $\mathrm{NO}_{2}$, $\mathrm{N}_{2} \mathrm{O}_{4}$ and $\mathrm{N}_{3} \mathrm{O}_{4}$, among others [24].

The demonstration of Kefiran anti-inflammatory performance (as compared to a gold standard biomaterial-HA) is highly relevant as it may induce cell protection in contexts of high oxidative stress. In fact, Kefiran polysaccharide exhibited excellent NO scavenging activity, leading to the reduction of the nitrite concentration in the medium.

Oxidative stress is a promoter of cell death and causes severe interferences in the normal physiological functioning of the host. Thus, the results obtained in our research justify a potential advantage of Kefiran biopolymer as a bioactive molecule for cell protection in oxidative stress environments, including inflammation contexts. Our research demonstrated that Kefiran represented a great scavenger for reactive oxygen species and reactive nitrogen species, which is greatly relevant taking into account its potential pharmaceutical application. It is important to highlight that the potential contribution of any biomaterial to oxidative stress is very relevant when assessing biocompatibility of new biomaterials candidates. In fact, the demonstration of antioxidant and anti-inflammatory properties is important in order to prove that the biomaterial candidate does not contribute to any pro-oxidative stress.

\subsection{Analysis of cytotoxicity of Kefiran using human primary cells}

It is important to point out that the incorporation of Kefiran extract in the medium culture improved the viability and the metabolic activity of hASCs. This is especially promising as these stem cells present the ability to differentiate into several lineages and display a tremendous potential for tissue engineering and regenerative medicine applications $[35,36]$.

The L929 cell line is widely used as model for in vitro evaluation of the cytotoxicity activity of an extract. However, due to immortalization, the response of L929 cells might diverge from primary cells such as hASCs. In this sense, no cytotoxicity of Kefiran polysaccharide with hASCs presented an important proof of the possibility of Kefiran use in cartilage and/or bone regeneration. Therefore, further assays on cell-loaded Kefiran scaffolds in in vivo model will be invaluable for the development of this polysaccharide as suitable biomaterial for cartilage and/or bone tissue regeneration.

\section{Conclusions}

The present research showed that Kefiran polysaccharide extracted from kefir grains possesses a wide-ranging beneficial therapeutic effects and health-promoting properties. In fact, Kefiran demonstrated a potential antioxidant performance against reactive oxygen species, highlighting Kefiran potential in providing cell protection in environments of oxidative stress. Moreover, this polysaccharide considerably induced NO, which could suggest that this biopolymer is an interesting immunostimulator. The results obtained substantiate our knowledge on the biological performance such as antioxidant and anti-inflammatory properties, and cytotoxicity effect of Kefiran polysaccharide; and encourage the use of this promising biopolymer as an alternative or adjunct treatment to promote tissue repair and regeneration while reducing the inflammation in $\mathrm{OA}$ context. 
Acknowledgements Hajer Radhouani, Cristiana Gonçalves and F. Raquel Maia were supported by grants with reference SFRH/BPD/ 100957/2014, SFRH/BPD/94277/2013 and SFRH/BPD/117492/2016, respectively of Fundação para a Ciência e a Tecnologia (FCT) from Portugal. JM Oliveira also would like to thank FCT for the fund provided under the program Investigador FCT 2015 (IF/01285/2015).

\section{Compliance with ethical standards}

Conflict of interest The authors declare that they have no conflict of interest.

\section{References}

1. Zhang W, Ouyang H, Dass CR, Xu J. Current research on pharmacologic and regenerative therapies for osteoarthritis. Bone Res. 2016;4:15040 https://doi.org/10.1038/boneres.2015.40.

2. Ondresik M, Maia FRA, Morais AD, Gertrudes AC, Bacelar AHD, Correia C, et al. Management of knee osteoarthritis. Current status and future trends. Biotechnol Bioeng. 2017;114(4):717-39. https://doi.org/10.1002/bit.26182.

3. Mushtaq S, Choudhary R, Scanzello CR. Non-surgical treatment of osteoarthritis-related pain in the elderly. Curr Rev Musculoskelet Med. 2011;4(3):113-22. https://doi.org/10.1007/s12178011-9084-9.

4. Kristjansson B, Honsawek S. Current perspectives in mesenchymal stem cell therapies for osteoarthritis. Stem Cells Int. 2014. 2014:1-13. Artn 194318 https://doi.org/10.1155/2014/194318.

5. Mao AS, Mooney DJ. Regenerative medicine: current therapies and future directions. Proc Natl Acad Sci USA. 2015;112 (47):14452-9. https://doi.org/10.1073/pnas.1508520112.

6. Fisher MB, Mauck RL. Tissue engineering and regenerative medicine: recent innovations and the transition to translation. Tissue Eng Part B Rev. 2013;19(1):1-13. https://doi.org/10.1089/ ten.TEB.2012.0723.

7. Edgar L, McNamara K, Wong T, Tamburrini R, Katari R, Orlando G. Heterogeneity of scaffold biomaterials in tissue engineering. materials (Basel). 2016;9(5):332-353. https://doi.org/10.3390/ma 9050332.

8. El-Sherbiny IM, Yacoub MH. Hydrogel scaffolds for tissue engineering: progress and challenges. Glob Cardiol Sci Pract. 2013;2013(3):316-42. https://doi.org/10.5339/gcsp.2013.38.

9. Prestwich GD. Hyaluronic acid-based clinical biomaterials derived for cell and molecule delivery in regenerative medicine. $\mathbf{J}$ Control Release. 2011;155(2):193-9. https://doi.org/10.1016/J. Jconrel.2011.04.007.

10. Borzacchiello A, Russo L, Malle BM, Schwach-Abdellaoui K, Ambrosio L. Hyaluronic acid based hydrogels for regenerative medicine applications. Biomed Res Int. 2015;2015:871218 https:// doi.org/10.1155/2015/871218.

11. Fakhari A, Berkland C. Applications and emerging trends of hyaluronic acid in tissue engineering, as a dermal filler and in osteoarthritis treatment. Acta Biomater. 2013;9(7):7081-92. https://doi.org/10.1016/j.actbio.2013.03.005.

12. Elsayed EA, Farooq M, Dailin D, El-Enshasy HA, Othman NZ, Malek R, et al. In vitro and in vivo biological screening of kefiran polysaccharide produced by Lactobacillus kefiranofaciens. Biomed Res-India. 2017;28(2):594-600.

13. Kooiman P. The chemical structure of kefiran, the water-soluble polysaccharide of the kefir grain. Carbohydr Res. 1968;7:200-1. https://doi.org/10.1016/S0008-6215(00)81138-6.

14. de Oliveira Leite AM, Miguel MA, Peixoto RS, Rosado AS, Silva JT, Paschoalin VM. Microbiological, technological and therapeutic properties of kefir: a natural probiotic beverage. Braz $\mathrm{J}$ Microbiol. 2013;44(2):341-9. https://doi.org/10.1590/S151783822013000200001

15. Manoto SL, Maepa MJ, Motaung SK. Medical ozone therapy as a potential treatment modality for regeneration of damaged articular cartilage in osteoarthritis. Saudi. J of Biol Sci. 2018;25(4):672-79. https://doi.org/10.1016/j.sjbs.2016.02.002.

16. Radhouani H, Gonçalves C, Oliveira JM, Reis RL. Kefiran for use in regenerative medicine and/ortissue engineering. A4TEC Association for the advancement of tissue engineering and cell basedtechnologies \& therapies. 2018; WO/2018/042405.

17. Qi H, Zhang Q, Zhao T, Hu R, Zhang K, Li Z. In vitro antioxidant activity of acetylated and benzoylated derivatives of polysaccharide extracted from Ulva pertusa (Chlorophyta). Bioorg \& Med Chem Lett. 2006;16:2441-5. https://doi.org/10.1016/j.bmcl. 2006.01.076.

18. Singhal M, Ratra P. Antioxidant activity, total flavonoid and total phenolic content of musa acuminate peel extracts. Glob J Pharmacol. 2013;7(2):118-22.

19. El SN, Karakaya S. Radical scavenging and iron-chelating activities of some greens used as traditional dishes in Mediterranean diet. Int J Food Sci Nutr. 2004;55(1):67-74. https://doi.org/ 10.1080/09637480310001642501.

20. Nagai T, Nagashima T, Suzuki N, Inoue R. Antioxidant activity and angiotensin I-converting enzyme inhibition by enzymatic hydrolysates from bee bread. Z Naturforsch C. 2005;60(12):133-8.

21. Nishikimi M, Roa NA, Yogi K. Measurement of superoxide dismutase. Biochem Biophys Res Commun. 1972;46:849-54.

22. Naithani V, Singhal AK, Chaudhary M. Comparative evaluation of metal chelating, antioxidant and free radical scavenging activity of TROIS and six products commonly used to control pain and inflammation associated with arthritis. Int J Drug Dev \& Res. 2011;3(4):208-16.

23. Ye SH, Liu F, Wang JH, Wang H, Zhang MP. Antioxidant activities of an exopolysaccharide isolated and purified from marine Pseudomonas PF-6. Carbohyd Polym. 2012;87(1):764-70. https://doi.org/10.1016/j.carbpol.2011.08.057.

24. Perez-Torres I, Guarner-Lans V, Rubio-Ruiz ME. Reductive stress in inflammation-associated diseases and the pro-oxidant effect of antioxidant agents. Int J Mol Sci. 2017;18(10):2098-2126. https:// doi.org/10.3390/ijms18102098.

25. Aparadh VT, Naik VV, Karadge BA. Antioxidantive properties (TPC, DPPH, FRAP, Metal chelating ability, reducing power and TAC) within some cleome species. Ann di Bot. 2012;2:49-56.

26. Liang TW, Tseng SC, Wang SL. Production and characterization of antioxidant properties of exopolysaccharide(s) from peanibacillus mucilaginosus TKU032. Mar Drugs 2016;14(2):40-52. https://doi.org/10.3390/md14020040.

27. Flora SJ. Structural, chemical and biological aspects of antioxidants for strategies against metal and metalloid exposure. Oxid Med Cell Longev. 2009;2(4):191-206. https://doi.org/10.4161/ oxim.2.4.9112.

28. Wang J, Hu S, Nie S, Yu Q, Xie M. Reviews on mechanisms of in vitro antioxidant activity of polysaccharides. Oxid Med Cell Longev. 2016;2016:5692852 https://doi.org/10.1155/2016/ 5692852

29. Liu SH, Sun SW, Tian ZF, Wu JY, Li XL, Xu CP. Antioxidant and hypoglycemic activities of exopolysaccharide by submerged culture of inocutus hispidus. Indian J Pharm Sci. 2015;77 (3):361-5.

30. Wang Y, Yang Z, Wei X. Antioxidant activities potential of tea polysaccharide fractions obtained by ultra filtration. Int $\mathrm{J}$ Biol Macromol. 2012;50(3):558-64. https://doi.org/10.1016/j.ijbioma c.2011.12.028. 
31. Guo S, Mao W, Han Y, Zhang X, Yang C, Chen Y, et al. Structural characteristics and antioxidant activities of the extracellular polysaccharides produced by marine bacterium Edwardsiella tarda. Bioresour Technol. 2010;101(12):4729-32. https:// doi.org/10.1016/j.biortech.2010.01.125.

32. Li HF, Xu JA, Liu YM, Ai SB, Qin F, Li ZW, et al. Antioxidant and moisture-retention activities of the polysaccharide from Nostoc commune. Carbohyd Polym. 2011;83(4):1821-7. https:// doi.org/10.1016/j.carbpol.2010.10.046.

33. Driessche TrsV, Guisset J-L, Petiau-deVries GM. The redox state and circadian rhythms. Springer; Springer Netherlands 2000; XII, 284. https://doi.org/10.1007/978-94-015-9556-8.
34. Gutierrez RM, Baez EG. Evaluation of antidiabetic, antioxidant and antiglycating activities of the Eysenhardtia polystachya. Pharmacogn Mag. 2014;10(Suppl 2):S404-18. https://doi.org/10. 4103/0973-1296.133295.

35. Popa E, Reis R, Gomes M. Chondrogenic phenotype of different cells encapsulated in kappa-carrageenan hydrogels for cartilage regeneration strategies. Biotechnol Appl Biochem. 2012;59 (2):132-41. https://doi.org/10.1002/bab.1007.

36. Santo VE, Popa EG, Mano JF, Gomes ME, Reis RL. Natural assembly of platelet lysate-loaded nanocarriers into enriched 3D hydrogels for cartilage regeneration. Acta Biomater. 2015;19:56-65. https://doi.org/10.1016/j.actbio.2015.03.015. 